\title{
An international exchange observership at Yale University
}

A Ugandan physician experience

Abdu Kisekka Musubire, MBChB, MMed

Neurology ${ }^{\circledR}$ 2019;92:582-584. doi:10.1212/WNL.0000000000007139

Neurologic diseases are the leading cause group of disability-adjusted life-years (DALYs) and the second leading cause group of death, with most DALYs and deaths occurring in low-income countries. ${ }^{1}$ The WHO has documented a deficiency of neurologists in low-income countries (0.03-0.13 per 100,000 population), which contrasts with upper-middle income and highincome countries (1.09-4.5 per 100,000 population). ${ }^{2}$ Approximately 26 million people live in sub-Saharan African (SSA) nations where there are no neurologists. ${ }^{3}$ Furthermore, there are few opportunities to receive clinical training in neurology within Africa, with fewer than 10 countries with neurology training programs. ${ }^{4}$ The scarcity of neurologists not only leads to poor patient outcomes but also discourages the young generation of doctors in countries such as Uganda from a career in neurology. ${ }^{5}$

There have been several strategies to accelerate neurology training in the SSA region, ranging from formal training obtained through established fellowships and Master's of Science (MSc) programs in neurology to observerships abroad and apprenticeships locally. MSc is a coursework-based 2-year program offered to students who have completed a Master's degree in medicine in which academic qualification is obtained after completion of training. Apprenticeship is an informal system of obtaining experience by working under a trained neurologist for several years with no examinations and no certification. The World Federation of Neurology, with a goal of increasing the number of neurologists, has proposed that neurology training begin in existing training locations in Africa because it is less expensive and reduces the possibility of brain drain. ${ }^{5}$ However, in most cases, the physicians must pay for these fellowships or MSc programs. Observerships and apprenticeships may be more favorable options. I first entered the specialty of neurology as an apprentice for 6 years under a neurologist at Mulago Hospital. Mulago Hospital is a 1,500-bed tertiary care center that serves as the main teaching hospital for Makerere University in Kampala, Uganda.

\section{Observership at Yale}

Building on my apprenticeship, my observership within the Yale Department of Neurology was one of the measures used to enhance my neurology education in Uganda under the Makerere University/Yale University collaboration. This collaboration has been in existence since 2002 between the departments of internal medicine at Yale University and Makerere University. Through this collaboration, the faculty and students from Yale and Makerere University work and learn together with the goal of improving care at Mulago National Referral Hospital. Several Makerere faculty members have benefited from this collaboration by completing an observership at Yale in the disciplines of cardiology, endocrinology, gastroenterology, pulmonology, and emergency medicine. In my case, the collaboration was extended to include the Yale department of neurology.

I began my year-long clinical observership in September 2014. On my arrival, I had a series of meetings with the directors of global health, the neurology residency program director, and the
Correspondence Dr. Musubire amusubire@yahoo.com

RELATED ARTICLE

Global \& Community Health: A perspective on neurologic care at Mulago Hospital in Uganda

Page 579 
neurology chair. I connected with 2 mentors with experience working in resource-limited settings, and we set up goals and a rotation schedule to acquire skills that would be most beneficial when I returned to Uganda. For example, my rotations were on the general neurology and stroke wards, neurocritical care unit, as well as headache, movement disorders, neuromuscular, epilepsy, neuro-oncology, and neuroinfectious clinics. We agreed to have regular monthly meetings with the mentors and the residency program director to discuss my progress. I was given full access to all the faculty, academic sessions, and materials available to the neurology residents and fellows and was trained in Health Insurance Portability and Accountability Act regulations in order to be able to access the patients' electronic medical records I observed on the wards and clinics. I underwent several medical screening procedures and immunizations to allow me access to the wards but was not allowed to examine patients. We used a shadow system where I sat in with another clinician seeing the patients with the patients' verbal consent. The shadow system though builds little confidence for clinical practice. This observership was jointly funded by a Medical Education Partnership Initiative grant from Makerere University (neurology linked program), a Yale-Mulago Medical Fellowship Corporation grant, and Mulago National Referral Hospital.

\section{Education}

In Uganda, residents start work at 8:00 AM, with an academic session that ends around 9:30 AM, followed by bedside ward rounds until 1:00 PM, followed by a lunch break. The afternoon is mainly focused on lectures. The major differences between my experience in the US observership and Uganda include the high patient load at Mulago Hospital (30-50 patients), long turnaround ( 24 hours or more) time for most investigations, less oversight by supervising physicians, and more lecture sessions with less time dedicated to clinical activities, as most patients are reviewed once daily.

\section{Clinical care}

During my observership, I saw that the focus is not only on high-quality patient care but also patient satisfaction, a fundamental part of the US insurance-based health care system. Uganda offers a free health care model but several services, such as radiologic investigations, are paid for out of pocket by the patient. A clinician spends much time informing and educating the patient about the required investigations like head $\mathrm{CT}$, treatments, and their costs, which is distressing for the patient and delays appropriate care. I am used to seeing patients who come late to the hospital with several complications in addition to their neurologic diagnosis. Neurology is a young discipline in Uganda, with no subspecialization, hence no challenges of multiple physician visits. Emergency care is lacking in Uganda in many specialized areas like thrombolysis in stroke. Communication between the doctor and patient at home is different from that at Yale. I come from an environment where it is difficult to talk about death and other poor prognostic events around very sick persons, but we also have few mechanical ventilators, where the end-of-life discussions are critical. The health care system in Uganda is challenged by lack of adherence to the referral system and patient appointments and consultations across disciplines since there is no appropriate telephone system or pagers in place.

\section{Benefits and challenges}

My year-long observership at Yale gave me more exposure to teaching and communication skills. I feel more comfortable talking about poor prognosis, such as in cases of motor neuron diseases. I was introduced to skills like botulinum toxin treatment not available in Uganda. I was also introduced to many free educational resources in neurology available on the Internet that I share with colleagues since Internet is available throughout much of Uganda.

Implementing knowledge learned will be limited by the lack of investigative resources like CTs and MRI, which are still limited in our environment. Where available, they remain expensive for many patients. Teaching and mentoring skills learned are limited by the large number of students under one supervisor (sometimes up to 8-10 students at a time). Patient communication skills learned will be limited by the large patient load of up to 40 patients on a ward round with limited patient privacy and lack of confirmation of diagnosis (no investigations). In some cases, talking is hampered by hopelessness of the situation, like trying to resuscitate a patient who will require intensive care services that are not readily available in many situations. Some specializations are also not yet recognized by the government regulatory bodies, which poses a challenge.

Patients' delay in seeking care, out-of-pocket health financing, large patient volumes, and lack of referral system contribute to the quality of care we offer in Uganda. There is a need to train more specialized doctors to build a critical mass of interest in neurology and work on accreditation issues in neurology in Uganda.

\section{Acknowledgment}

The author thanks the Yale Global Health Division, headed by Dr. Asghar Rastegar and Dr. Tracy Rabin; The Yale Department of Neurology, headed by Dr. David A. Hafler; The Yale Neurology Residency Program Director, Dr Jeremy Moeller; Dr. Jason Sico and Dr. Ana-Claire Meyer; Makerere University Department of Medicine chair, Prof. Moses Kamya and Prof. Elly Katabira; the Makerere University/ Yale University collaboration; the Neurology-Medical Education Partnership Initiative program; and Mulago Hospital, management headed by Dr. Byarygaba Baterana.

\section{Study funding}

No targeted funding reported. 


\section{Disclosure}

The author reports no disclosures relevant to the article. Go to Neurology.org/N for full disclosures.

\section{References}

1. Global Brain Disorders Neurological Disorders Collaborator Group. Global, regional, and national burden of neurological disorders during 1990-2015: a systematic analysis for the Global Burden of Disease Study 2015. Lancet Neurol 2017;16:877-897.
2. World Health Organization, World Federation of Neurology. ATLAS Country Resources for Neurological Disorders, 2nd ed. Geneva: World Health Organization; 2017.

3. Berkowitz AL. Neurology education in resource-limited settings. Neurology 2014;82: 1463-1464.

4. Bower JH, Diop AG, Gouider R, Schmutzhard E. Addressing neurologic needs in subSaharan Africa: an opportunity for multisociety cooperation. Neurology 2014;83: 1207-1209.

5. Aarli JA, Diop AG, Lochmuller H. Neurology in sub-Saharan Africa: a challenge for World Federation of Neurology. Neurology 2007;69:1715-1718.

\section{Subspecialty Alerts by E-mail!}

Customize your online journal experience by signing up for e-mail alerts related to your subspecialty or area of interest. Access this free service by clicking on the "My Alerts" link on the home page. An extensive list of subspecialties, methods, and study design choices will be available for you to choose from-allowing you priority alerts to cutting-edge research in your field!

\section{Did You Know...}

...you can browse by subspecialty topics on Neurology.org?

Go to: Neurology.org and click on "Topics" in the top navigation bar.

\section{Sign Up for the AAN's Axon Registry}

The AAN encourages its US members to show their interest in participating in the Axon Registry by signing up today.

Use the Axon Registry to:

- Simplify reporting requirements under MACRA's Quality Payment Program and avoid penalties while reducing your administrative burden

- Meet your MOC Part IV requirements and waive up to eight credits of Part II Self-Assessment

- Choose from 22 AAN neurology-specific quality measures that fit your practice

- Use data to understand your practice and identify where improvements can be made to patient care

- Manage your patients at a population level; look at a specific group of patients based on conditions, risk factors, demographics or outcome

- Demonstrate your value to payers when negotiating reimbursement

- Enjoy multi-year, fee-free access when you sign the agreements and integrate your EHR with the registry

Learn more at AAN.com/view/Axon and send your questions to registry@aan.com. 


\section{Neurology}

\section{An international exchange observership at Yale University: A Ugandan physician experience}

Abdu Kisekka Musubire

Neurology 2019;92;582-584

DOI 10.1212/WNL.0000000000007139

This information is current as of March 18, 2019

\section{Updated Information \&} Services

\section{References}

Subspecialty Collections

Permissions \& Licensing

Reprints including high resolution figures, can be found at: http://n.neurology.org/content/92/12/582.full

This article cites 4 articles, 3 of which you can access for free at: http://n.neurology.org/content/92/12/582.full\#ref-list-1

This article, along with others on similar topics, appears in the following collection(s):

Access to care

http://n.neurology.org/cgi/collection/access_to_care All Education

http://n.neurology.org/cgi/collection/all_education

All global neurology

http://n.neurology.org/cgi/collection/all_global_neurology

Training-international

http://n.neurology.org/cgi/collection/training_international

Information about reproducing this article in parts (figures,tables) or in its entirety can be found online at:

http://www.neurology.org/about/about_the_journal\#permissions

Information about ordering reprints can be found online:

http://n.neurology.org/subscribers/advertise

Neurology ${ }^{\circledR}$ is the official journal of the American Academy of Neurology. Published continuously since 1951, it is now a weekly with 48 issues per year. Copyright @ 2019 American Academy of Neurology. All rights reserved. Print ISSN: 0028-3878. Online ISSN: 1526-632X.

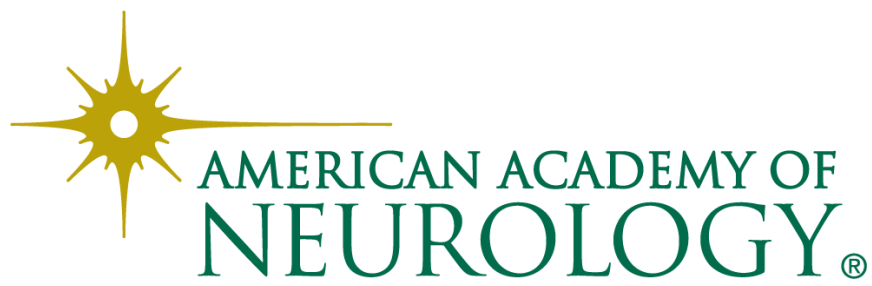

